Sharif University of Technology
Scientia Iranica
SCIENTIA
I RAN ICA

\title{
One-pot solvent-free synthesis of pyranonaphthoquinone-fused spirooxindoles catalyzed by SBA-IL
}

\author{
G. Mohammadi Ziarani ${ }^{a, *}$, H. Mollabagher ${ }^{a}$, N. Lashgari ${ }^{a}$, and A. Badiei ${ }^{b}$ \\ a. Department of Chemistry, Alzahra University, Tehran, P.O. Box 1993891176, Iran. \\ b. School of Chemistry, College of Science, University of Tehran, Tehran, 14155-6455, Iran.
}

Received 12 April 2017; received in revised form 18 October 2017; accepted 26 June 2018

\author{
KEYWORDS \\ SBA-IL; \\ Multicomponent \\ reaction; \\ Spirooxindole; \\ Isatin; \\ Mesoporous silica; \\ Heterogeneous \\ catalyst.
}

\begin{abstract}
In this research, ionic liquid modified SBA-15 mesoporous material (SBA-IL) as a recyclable, heterogeneous catalyst efficiently catalyzed the synthesis of pyranonaphthoquinone-fused spirooxindoles through the one-pot three-component reaction of isatin derivatives, activated methylene reagents, and 2-hydroxy-1,4-naphthoquinone. The reactions were performed under microwave irradiation and solvent-free conditions. The synthesized SBA-IL was characterized by SEM, FT-IR, nitrogen adsorption-desorption, and thermogravimetric analyses. Excellent chemical yield, short reaction time, mild reaction condition, easy workup procedures, and reusability of catalyst are noteworthy advantages of this protocol.
\end{abstract}

(C) 2018 Sharif University of Technology. All rights reserved.

\section{Introduction}

Since the discovery of a class of periodic mesoporous silica, known as the M41S phase, by the Mobil Oil Company in 1992 [1], mesoporous silica materials have gained considerable attention. SBA-15 materials as a kind of mesoporous silica possess a number of special physical and chemical properties such as well-ordered hexagonal structure, high surface area, and high thermal stability that make them a unique inorganic solid support. Chemical modification of SBA-15 can create a wide variety of novel materials with improved catalytic properties as compared to conventional catalysts [2].

\footnotetext{
*. Corresponding author. Tel.: +982188041344; Fax: +982188041344

E-mail address: gmziarani@hotmail.com (G. Mohammadi Ziarani)
}

doi: $10.24200 /$ sci. 2018.20741
Besides their use as catalysts [3], modified SBA-15 silica materials are considered as a promising class of materials in various areas including chemosensors [4,5], adsorbents [6], gas storage [7], drug delivery [8,9], etc. Among different organically modified SBA-15 materials, immobilization of Ionic Liquids (ILs) onto solid-based materials has received significant attention of researchers. ILs have emerged as promising environmentally benign media, not only as favorable solvents for catalysis but also as green catalysts themselves in various reactions [10]. Although the recovery of involatile IL from reactions is achievable in many cases, liquid-phase processing is still required. The support of ILs on solids to provide heterogeneous systems gave significant improvement in this context, in which simpler workup procedures via filtration/decantation of the solid material were allowed [11].

Heterocyclic compounds have received tremendous attention in the chemical literature as a result of their abundance in natural products and their diverse 


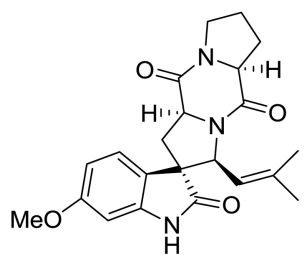

Spirotryprostatin A<smiles>CC(C)=CCN1C(=O)C2CCCN2C(=O)C12CC(C)(C)C21C(=O)Nc2ccccc21</smiles>

Spirotryprostatin B

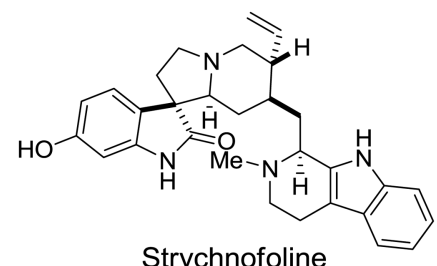

Strychnofoline

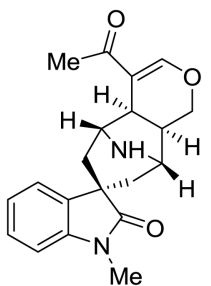

Alstonisine<smiles>[R]c1ccc2c(c1)C1(CCN(C)C1)C(=O)N2</smiles>

$\mathrm{R}=\mathrm{OMe}$, Horsfiline $\mathrm{R}=\mathrm{H}$, Coerulescine<smiles>CC(C)CC1NCCC12C(=O)Nc1cc(O)ccc12</smiles>

Isoelacomine<smiles>[Y6][C@H]1OC=C(C(=O)OC)[C@H]2C[C@H]3N(CC[C@@]34C(=O)Nc3ccccc34)C[C@@H]21</smiles>

Pteropodine

Figure 1. Representative spirooxindole natural products.

and profound biological activities $[12,13]$. In this respect, indole nuclei represent an important class of bioactive heterocyclic compounds in organic and medicinal chemistry [14]. In addition, it has been reported that the biological activity will be highly improved in C-3 spiroindoline derivatives [15]. The resulting spirooxindoles are found in a variety of natural products and bioactive molecules (Figure 1).

Isatin and its derivatives also possess a variety of useful biological properties and using isatin as precursor in multicomponent reactions usually leads to the formation of spiro-fused cyclic frameworks [16-18]. In the literature, there exist few reports on multicomponent entries to the synthesis of pyranonaphthoquinonefused spirooxindoles. Ghahremanzadeh et al. [19] reported a three-component condensation of isatins, activated methylene reagents, and 2-hydroxy-1,4naphthoquinone catalyzed by $p$-toluenesulfonic acid ( $p$ TSA) in refluxing water. This reaction was also carried out in the presence of TBAB (tetrabutyl ammonium bromide) in water and solvent-free conditions [20]. Pyranonaphthoquinone-fused spirooxindoles were also prepared by the organocatalytic asymmetric cascade Michael cyclization reaction of 2-hydroxynaphthalene1,4-diones to isatylidene malononitriles [21,22].

In this context, although some noteworthy advances have been achieved in recent years, the development of new and efficient methods utilizing a more appropriate and more accessible catalyst remains in high demand for the construction of pyranonaphthoquinonefused spirooxindoles. Taking these studies into account and our own experience in the field of modification and application of nanoporous heterogeneous solid catalysts in organic reactions [23-31], in this paper, we explore the catalytic activity of SBA-IL as a highly efficient catalyst in the synthesis of pyranonaphthoquinone- fused spirooxindoles. Previously, we have reported the application of SBA-IL as a nano-catalyst in successful synthesis of benzo[4,5]imidazo[1,2-a]pyrimidines [32] and polyhydroquinoline derivatives [33].

\section{Experimental}

\subsection{Materials and methods}

The chemicals employed in this work were obtained from Merck and Aldrich chemical companies. Melting points were measured using an Electrothermal 9200 apparatus through the capillary tube method. IR spectra were recorded from $\mathrm{KBr}$ disks using an FTIR Bruker Tensor 27 instrument in the range of 400$4000 \mathrm{~cm}^{-1}$. The ${ }^{1} \mathrm{H} \mathrm{NMR}$ and ${ }^{13} \mathrm{C} \mathrm{NMR}$ were run on a Bruker DPX at 250 and $62.5 \mathrm{MHz}$ in DMSO$d_{6}$ as solvent and tetramethylsilane (TMS) as internal standard. SEM analysis was performed on a field emission scanning electron microscope (FESEM, Hitachi S-4160 Japan). Thermogravimetric analysis (TGA) was carried out using a TGA Q50 V6.3 Build 189 instrument from ambient temperature to $1000^{\circ} \mathrm{C}$ with a ramp rate of $10^{\circ} \mathrm{C} / \mathrm{min}$. Surface area was measured using the Brunauer-Emmett-Teller (BET) method and pore size distributions were calculated from the nitrogen isotherms by Barrett-Joyner-Halenda (BJH) method.

\subsection{Catalyst preparation}

SBA-IL was synthesized based on the method reported before [32]. The overall procedure for preparation of SBA-IL is illustrated in Scheme 1. SBA-IL was prepared by synthesizing SBA-15 and performing one simple subsequent functionalization step using $N$ methyl- $N^{\prime}$-propyltrimethoxysilyl imidazolium chloride to afford SBA-IL. 


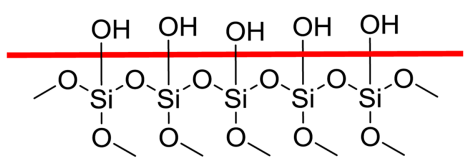

SBA-15

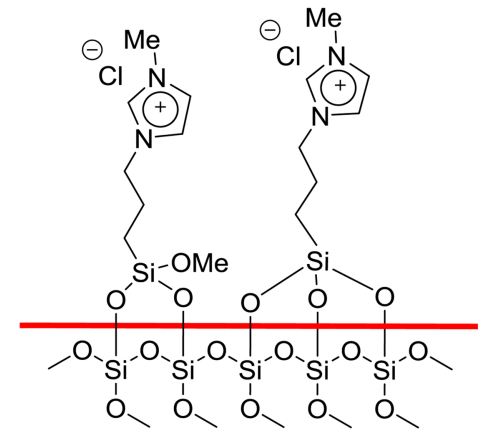

SBA-IL

Scheme 1. Preparation of ionic liquid functionalized SBA-15 (SBA-IL).

\subsection{General procedure for the synthesis of pyranonaphthoquinone-fused spirooxindoles $(4 a-h)$}

\subsubsection{Method A: Conventional heating}

SBA-IL (0.02 g) was added to a mixture of isatin derivatives (1 mmol), activated methylene reagents (1 mmol), and 2-hydroxynaphthalene-1,4-dione (1 mmol, $0.174 \mathrm{~g})$ under solvent-free conditions. The reaction mixture was stirred at $150^{\circ} \mathrm{C}$ for an approximate amount of time. The progress of the reaction was monitored by TLC using EtOAc/ $n$-hexane (1:2) as the eluent. Upon completion of the reaction, the crude product was dissolved in ethyl acetate. Since SBA-IL was insoluble in ethyl acetate, it was simply separated by filtration. Ethyl acetate was vaporized by heating and the solid pure product was obtained through recrystallization of the filtrate. All products were characterized by comparison of their physical data with those of known compounds reported in the literature. The catalyst was washed subsequently with ethanol, dried under vacuum, and reused several times without significant loss of activity.

\subsubsection{Method B: Microwave irradiation}

To a solution of isatin derivatives (1 $\mathrm{mmol})$, activated methylene reagents $(1 \mathrm{mmol})$, and 2hydroxynaphthalene-1,4-dione (1 mmol, $0.174 \mathrm{~g})$, SBAIL $(0.02 \mathrm{~g})$ was added and the mixture was stirred at room temperature. The mixture of the reaction was then irradiated in a domestic microwave oven for $8 \mathrm{~min}$ at $800 \mathrm{~W}$. The work-up procedure and characterization of compounds were same as those mentioned before.

\subsection{Spectral data of some representative products}

2.4.1. 2-Amino-5'-chloro-2',5,10-trioxo-5,10dihydrospiro[benzo[g]chromene-4,3'-indoline]-3carbonitrile $\mathrm{C}_{21} \mathrm{H}_{10} \mathrm{ClN}_{3} \mathrm{O}_{4}(4 \mathrm{~b})$

Yellow powder; mp 258-260 (dec); (93\% Method A, $90 \%$ Method B); FT-IR (KBr), $\nu\left(\mathrm{cm}^{-1}\right)$ : 3335, 3250, 3184, 2209, 1743, 1716, 1675, 1340 and $1207 .{ }^{1} \mathrm{H}$ NMR $\left(250 \mathrm{MHz}, \mathrm{DMSO}-d_{6}\right): \delta_{H}(\mathrm{ppm}) 6.87(1 \mathrm{H}, \mathrm{d}, J=8.2$ $\mathrm{Hz}, \mathrm{ArH}), 7.22-8.05$ (6H, m, ArH), $7.84\left(2 \mathrm{H}, \mathrm{bs}, \mathrm{NH}_{2}\right)$, $10.82(1 \mathrm{H}, \mathrm{s}, \mathrm{NH}) .{ }^{13} \mathrm{C}$ NMR $\left(62.5 \mathrm{MHz}, \mathrm{DMSO}-d_{6}\right)$ : $\delta_{\mathrm{C}}(\mathrm{ppm}) 48.7,56.7,111.4,117.2,119.1,124.9,126.3$, $126.4,126.6,129.1,130.7,130.9,134.9,135.2,136.7$, $141.1,151.1,159.1,176.7,177.7,182.3$.

\subsubsection{2-Amino-5'-iodo-2', 5,10-trioxo-5,10- dihydrospiro[benzo[g]chromene-4,3'-indoline]-3- carbonitrile $\mathrm{C}_{21} \mathrm{H}_{10} \mathrm{IN}_{3} \mathrm{O}_{4}$ (4d)}

Orange powder; mp 262-263 (dec); (94\% Method A, 90\% Method B); FT-IR (KBr), $\nu\left(\mathrm{cm}^{-1}\right)$ : 3444, 3381, 3159, 2215, 1737, 1667, 1652, 1334 and 1205. ${ }^{1} \mathrm{H}$ NMR (250 MHz, DMSO- $\left.d_{6}\right): \delta_{H}(\mathrm{ppm}) 6.83(1 \mathrm{H}, \mathrm{d}$, $J=8.2 \mathrm{~Hz}, \mathrm{ArH}), 7.35-8.54$ (8H, $m, \mathrm{ArH}$ and $\left.\mathrm{NH}_{2}\right)$, $10.81(1 \mathrm{H}, \mathrm{s}, \mathrm{NH}) .{ }^{13} \mathrm{C}-\mathrm{NMR}\left(62.5 \mathrm{MHz}, \mathrm{DMSO}-d_{6}\right)$ : $\delta_{\mathrm{C}}(\mathrm{ppm}) 56.8,60.2,111.9,114.0,117.2,119.1,126.4$, $126.6,127.6,130.8,130.9,132.0,134.9,135.2,137.1$, $141.5,151.1,159.1,176.7,177.6,182.3$.

\section{Results and discussion}

\subsection{The synthesis of pyranonaphthoquinone-fused spirooxindoles}

Due to our interest in application of nanoporous heterogeneous solid catalysts in organic reactions, herein, we report a facile synthesis of pyranonaphthoquinonefused spirooxindoles $\mathbf{4}$ from commercially available isatins $\mathbf{1}$, malononitrile $\mathbf{2}$, and 2-hydroxy-1,4naphthoquinone $\mathbf{3}$ catalyzed by nano-ordered SBA-IL. To date, many attempts have been devoted to the development of catalysis with ILs for fine chemical synthesis. In this context, solid catalysis with ILs can be a very promising candidate for developing green processes for the synthesis of various organic compounds [34]. Modification of surface of SBA-15 with imidazolium cations takes advantage of excellent features of both SBA-15 and ionic liquid [35-37].

In order to optimize the condition of reaction, initially, we screened the effect of solvent and temper- 
Table 1. The optimization of reaction condition.

\begin{tabular}{|c|c|c|c|c|c|}
\hline & 1 & 2 & 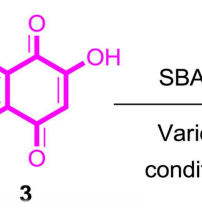 & & $\begin{array}{l}\mathrm{CN} \\
\mathrm{NH}_{2}\end{array}$ \\
\hline Entry & Catalyst & Solvent & Condition & Time (min) & Yield $(\%)^{a}$ \\
\hline 1 & SBA-IL & EtOH & Reflux & 180 & N.R \\
\hline 2 & SBA-IL & - & r.t. & 180 & N.R \\
\hline 3 & SBA-IL & - & $100^{\circ} \mathrm{C}$ & 60 & 50 \\
\hline 4 & SBA-IL & - & $120^{\circ} \mathrm{C}$ & 60 & 57 \\
\hline 5 & SBA-IL & - & $130^{\circ} \mathrm{C}$ & 60 & 65 \\
\hline 6 & SBA-IL & - & $150^{\circ} \mathrm{C}$ & 5 & 95 \\
\hline 7 & SBA-IL & - & $160^{\circ} \mathrm{C}$ & 5 & 90 \\
\hline 8 & - & - & $160^{\circ} \mathrm{C}$ & 60 & 25 \\
\hline 9 & SBA-IL & - & MW $(800 \mathrm{~W})$ & 8 & 94 \\
\hline
\end{tabular}

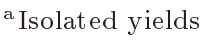

ature on the model reaction of isatin $\mathbf{1}$, malononitrile $\mathbf{2}$, and 2-hydroxy-1,4-naphthoquinone $\mathbf{3}$ in the presence of SBA-IL as the catalyst (Table 1). Using ethanol as the solvent was found to be ineffective on this reaction, resulting in a trace of the desired product after the reaction time was extended to $180 \mathrm{~min}$ (Table 1, entry 1). We then focused on reaction temperature for further investigation (Table 1, entries 2-7). The best result was obtained at the temperature of $150^{\circ} \mathrm{C}$ under solvent-free condition (Table 1, entry 6). Increasing the reaction temperature to $160^{\circ} \mathrm{C}$ did not increase the yield, significantly (Table 1 , entry 7 ). We also studied catalyst-free system at $160^{\circ} \mathrm{C}$ to screen the presence of catalyst. As shown in Table 1, entry 8, it was found that without any catalyst, only $25 \%$ product yield would be achieved after $60 \mathrm{~min}$. At the final evaluation step, we repeated the model reaction under microwave irradiation, which resulted in the isolation of the desired product in $94 \%$ yield within $8 \mathrm{~min}$ (Table 1 , entry 9 ). The amount of catalyst required for this reaction was also estimated. The model reaction was tested in the presence of $0.01,0.02,0.03$, and $0.04 \mathrm{~g}$ of catalyst and it was found that using $0.02 \mathrm{~g}$ of SBAIL as the catalyst under the optimized conditions was sufficient for the progress of the reaction. Increasing the amount of nanocatalyst to more than $0.02 \mathrm{~g}$ had no significant effect on the yield.

Figure 2 shows the synthesis of pyranonaphthoquinone-fused spirooxindole $\mathbf{4 a}$ as a function of the temperature and time. It can be seen that the yield of $\mathbf{4 a}$ increases with increase in reaction temperature until $150^{\circ} \mathrm{C}$, which is the optimum point. After this point, increasing the reaction temperature did not show a positive effect on the product yield, which could be due to decomposition of the product at higher

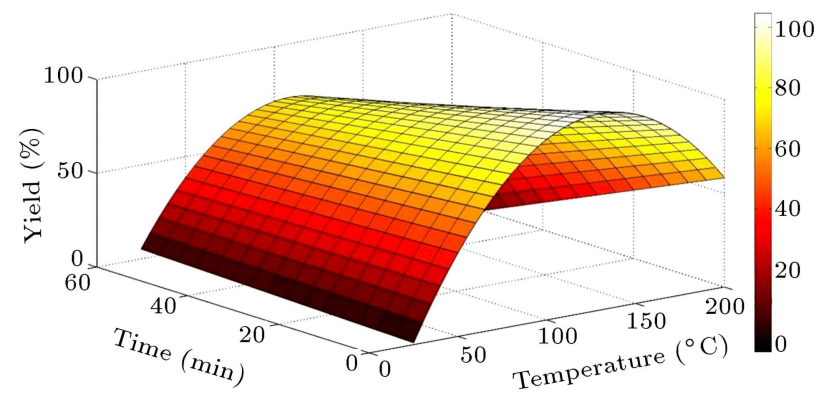

Figure 2. Synthesis of pyranonaphthoquinone-fused spirooxindole $\mathbf{4} \mathbf{a}$ as a function of the temperature and time.

temperature. As clearly visible in this figure, the yield of compound $\mathbf{4 a}$ was powerfully influenced by reaction temperature and time of the multicomponent process. In fact, due to the presence of SBA IL as a nano-reactor in this reaction, the reaction time was very short.

The optimized reaction conditions were then employed for library construction with seven isatin derivatives and two activated methylene reagents (Scheme 2). The corresponding pyranonaphthoquinone-fused spirooxindoles were synthesized successfully in high yields under both solvent-free conditions at $150^{\circ} \mathrm{C}$ and microwave irradiation. The results are summarized in Table 2. It was observed that isatins having either electron-donating (alkyl) or electron-withdrawing groups (halides) were well tolerated in the corresponding reaction.

A schematic illustration of the proposed mechanism for the catalytic efficiency of SBA-IL on the synthesis of pyranonaphthoquinone-fused spirooxindoles is shown in Scheme 3. It is reasonable to assume that first, the Knoevenagel condensation of isatin $\mathbf{1}$ and activated methylene reagents $\mathbf{2}$ in the presence of 
Table 2. One-pot three-component synthesis of pyranonaphthoquinone-fused spirooxindoles in the presence of SBA-IL.

\begin{tabular}{|c|c|c|c|c|c|c|c|c|}
\hline \multirow[t]{2}{*}{ No } & \multirow[t]{2}{*}{$\mathbf{R}^{1}$} & \multirow[t]{2}{*}{$1 \mathbf{R}^{2}$} & \multirow[t]{2}{*}{$\mathbf{R}^{3}$} & \multicolumn{2}{|c|}{ Method $A^{a}$} & \multirow{2}{*}{$\begin{array}{c}\text { Method } \mathbf{B}^{\mathrm{b}} \\
\text { Yield (\%) }\end{array}$} & \multirow[t]{2}{*}{ m.p. $\left({ }^{\circ} \mathrm{C}\right)$} & \multirow[t]{2}{*}{ m.p. $\left({ }^{\circ} \mathrm{C}\right)$} \\
\hline & & & & Time (min) & Yield (\%) & & & \\
\hline $4 a$ & $\mathrm{H}$ & $\mathrm{H}$ & $\mathrm{CN}$ & 5 & 95 & 94 & $293-295$ (dec) & 295 (dec) [19] \\
\hline $4 b$ & $\mathrm{H}$ & $5-\mathrm{Cl}$ & $\mathrm{CN}$ & 5 & 93 & 90 & $258-260(\mathrm{dec})$ & $224-226[21]$ \\
\hline $4 c$ & $\mathrm{H}$ & $5-\mathrm{Br}$ & $\mathrm{CN}$ & 5 & 87 & 85 & $275-278(\mathrm{dec})$ & 275 (dec) [19] \\
\hline $4 d$ & $\mathrm{H}$ & $5-\mathrm{I}$ & $\mathrm{CN}$ & 15 & 94 & 90 & $262-263(\mathrm{dec})$ & New \\
\hline $4 e$ & $\mathrm{H}$ & 5 -NO2 & $\mathrm{CN}$ & 10 & 95 & - & $288-291$ (dec) & 290 (dec) [19] \\
\hline $4 f$ & $\mathrm{Me}$ & $\mathrm{H}$ & $\mathrm{CN}$ & 3 & 97 & 95 & $263-266$ (dec) & 265 (dec) [19] \\
\hline $4 \mathrm{~g}$ & Et & $\mathrm{H}$ & $\mathrm{CN}$ & 3 & 96 & 92 & $208-210(\mathrm{dec})$ & 211 (dec) [19] \\
\hline $4 h$ & $\mathrm{H}$ & $\mathrm{H}$ & CO2Et & 15 & 93 & - & 266-267 & $268-270[38]$ \\
\hline
\end{tabular}

a Method A: Reaction condition: solvent-free at $150^{\circ} \mathrm{C}$

${ }^{b}$ Method B: Reaction condition: microwave irradiation for 8 minutes

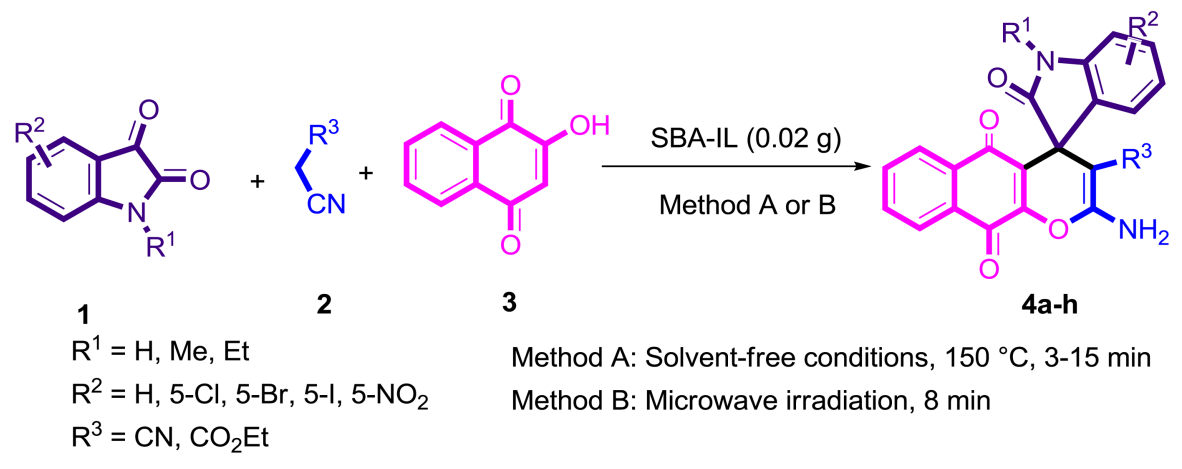

Scheme 2. Synthesis of pyranonaphthoquinone-fused spirooxindoles in the presence of SBA-IL.

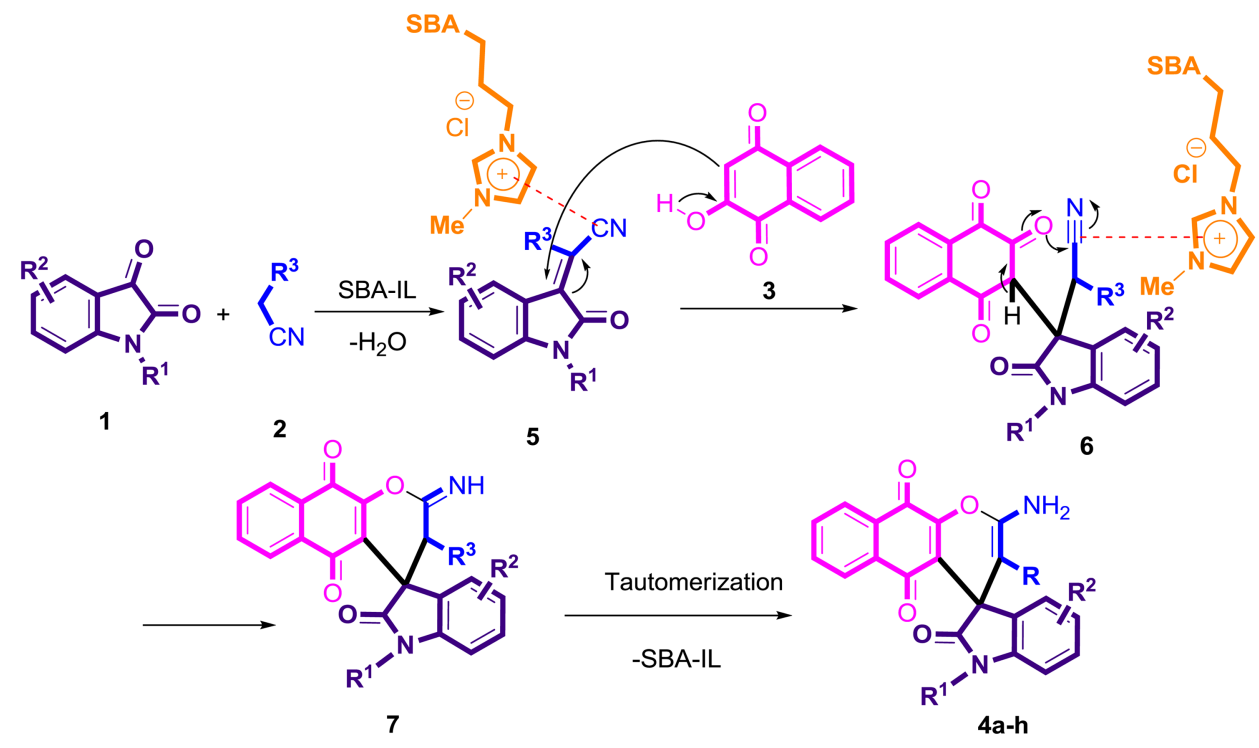

Scheme 3. Proposed reaction mechanism for the formation of pyranonaphthoquinone-fused spirooxindoles.

SBA-IL provides intermediate 5 . Then, intermediate 5 undergoes Michael-type addition of 2-hydroxy-1,4naphthoquinone $\mathbf{3}$ to give intermediate $\mathbf{6}$. The following cyclization of hydroxyl group to the cyano moiety and tautomerization leads to the final products 4ah [19].

Table 3 illustrates a comparison of the catalytic efficiencies of SBA-IL and other catalysts used in the synthesis of pyranonaphthoquinone-fused spirooxindole 4a. The results clearly indicate that the catalytic activity of SBA-IL is comparable and even superior to other existing methods (Table 3 ).

\subsection{Catalyst identification}

The structure of SBA-IL was characterized by SEM, FT-IR, nitrogen adsorption-desorption, and TGA anal- 
Table 3. Catalytic comparison of SBA-IL with some reports in the literature for the synthesis of pyranonaphthoquinone-fused spirooxindole $\mathbf{4 a}$.

\begin{tabular}{|c|c|c|c|c|c|c|}
\hline Entry & Catalyst & Solvent & Condition & Time (h) & Yield (\%) & Year (Ref.) \\
\hline 1 & $p$-TSA & $\mathrm{H}_{2} \mathrm{O}$ & Reflux & 7 & 90 & 2009 [19] \\
\hline 2 & $\mathrm{TBAB}^{\mathrm{a}}$ & $\mathrm{H}_{2} \mathrm{O}$ & Reflux & $55 \mathrm{~min}$ & 85 & 2011 [20] \\
\hline 3 & & $\mathrm{Et}_{2} \mathrm{O}$ & r.t. & 48 & 98 & 2014 [21] \\
\hline 4 & & Toluene & r.t. & 120 & 81 & 2015 [22] \\
\hline 5 & SBA-IL & - & $150^{\circ} \mathrm{C}$ & $5 \mathrm{~min}$ & 95 & This work \\
\hline
\end{tabular}

aTetrabutyl ammonium bromide.

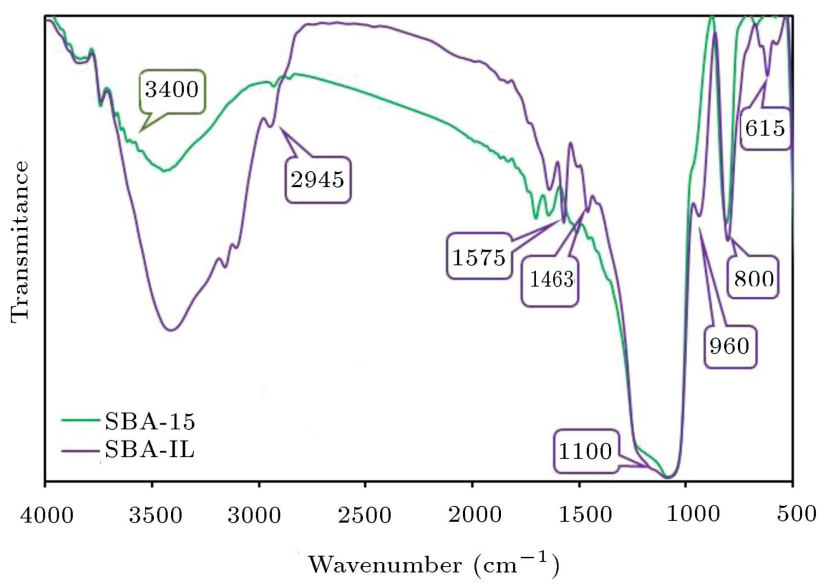

Figure 3. FT-IR spectra of SBA-15 and SBA-IL.

yses. Figure 3 shows the FT-IR spectra of SBA-15 and SBA-IL. As illustrated, both materials exhibit characteristic bands of mesoporous silica type materials, i.e., the bands at $800,960,1100$, and a wide peak at $3400 \mathrm{~cm}^{-1}$. The FTIR spectrum of SBA-IL showed new bands at $2945 \mathrm{~cm}^{-1}$ attributed to the vibrations of the $-\mathrm{CH}_{2}$ - groups of the propyl chains. Moreover, new bands at around 615,1463 , and $1575 \mathrm{~cm}^{-1}$ are related to the mono 4-substituted imidazole, C-H asymmetric stretch, and $\mathrm{C}=\mathrm{C}, \mathrm{C}=\mathrm{N}$ aromatic stretching vibrations, respectively. Thus, all observations confirm the successful grafting of imidazolium groups onto the pore walls of SBA-15.

The thermogram of SBA-IL shows several degradation steps corresponding to different mass losses (Figure 4). The initial degradation stage up to around $150^{\circ} \mathrm{C}$ is due to the removal of adsorbed $\mathrm{H}_{2} \mathrm{O}$ molecules from the catalyst. The subsequent major weight loss corresponds to the thermal decomposition of grafted

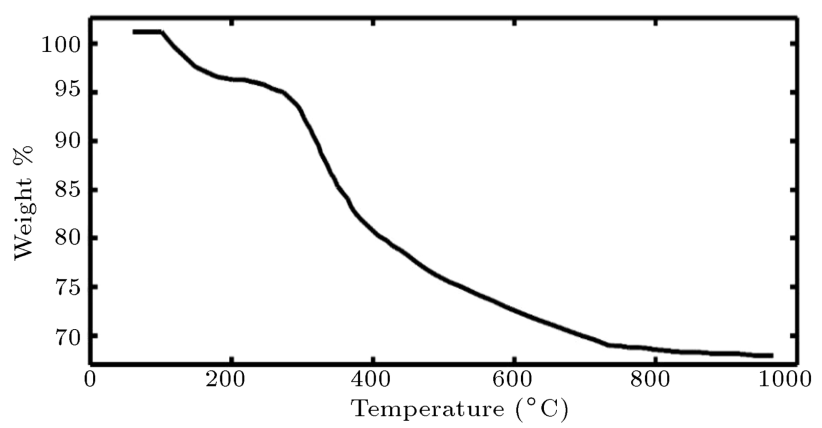

Figure 4. TGA curve of SBA-IL.

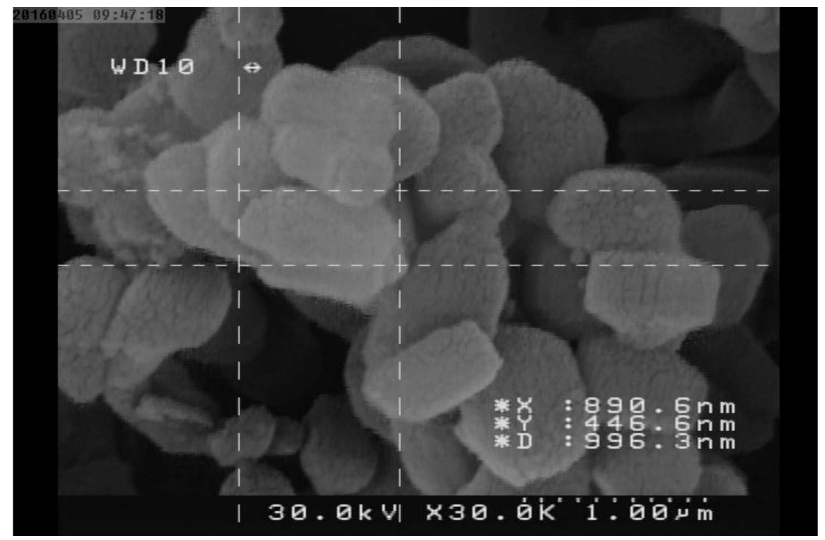

Figure 5. SEM image of SBA-IL.

propyl imidazolium groups, which is estimated to be about $2.0 \mathrm{mmol} \mathrm{g}^{-1}$.

SEM images of SBA-IL are shown in Figure 5. As shown, SBA-IL exhibited uniformly sized pores about 1-2 $\mu \mathrm{m}$, very similar to those of pure SBA-15, revealing the maintenance of morphology after surface functionalization.

The physical properties of the surface and poros- 
Table 4. Textural properties of SBA-15 and SBA-IL.

\begin{tabular}{|c|c|c|c|}
\hline Sample & $S_{\text {BET }}{ }^{a}\left(m^{2} \cdot g^{-1}\right)$ & $V^{a}\left(\mathrm{~cm}^{3} \cdot g^{-1}\right)$ & $\mathrm{D}_{\mathrm{BJH}}{ }^{\mathrm{a}}(\mathrm{nm})$ \\
\hline SBA-15 & 587 & 0.780 & 6.2 \\
\hline SBA-IL & 71 & 0.128 & 5.5 \\
\hline
\end{tabular}

${ }^{a} \mathrm{~S}_{\mathrm{BET}}$ : specific surface area; $\mathrm{V}$ : total pore volume; $\mathrm{D}_{\mathrm{BJH}}$ : average pore diameter.

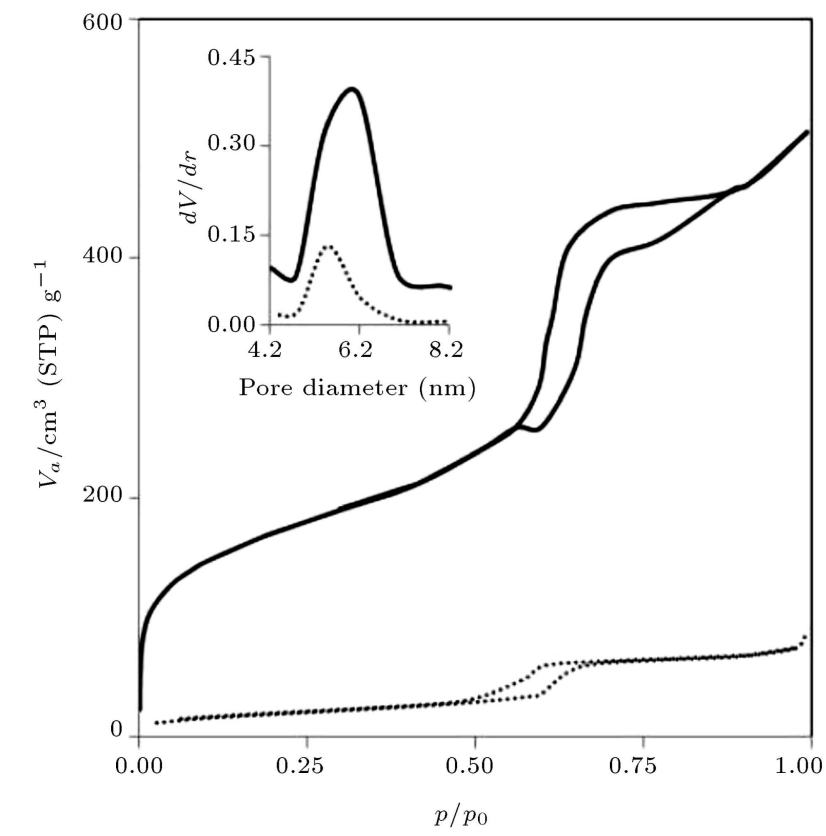

Figure 6. $\mathrm{N}_{2}$ adsorption-desorption isotherms of (a) SBA-15 and (b) SBA-IL. Inset: BJH pore size distribution curves.

ity variations of SBA-15 were further studied by recording the $\mathrm{N}_{2}$ adsorption-desorption isotherm of SBA-15 before and after the functionalization step (Figure 6) [32]. As shown, both isotherms exhibited a shape which was in agreement with the type IV nitrogen adsorption-desorption isotherms with $\mathrm{H} 1$ hysteresis loops corresponding to mesoporous materials [39]. This observation clearly confirms the preservation of the original structure of SBA-15 after functionalization. Table 4 provides the textural parameters of the samples. A decreasing trend in the three parameters confirmed successful grafting of organic moieties on the surface of SBA-15.

\subsection{Catalyst reusability}

Lastly, the recyclability of SBA-IL for the preparation of model product $4 \mathbf{a}$ was examined under the optimized conditions (solvent-free conditions at $150^{\circ} \mathrm{C}$ ). For this purpose, the catalyst was separated through a simple filtration after the first reaction run, washed with EtOH, and dried under vacuum. Then, the recovered catalyst was reused for the next run of the reaction. The recycling of the catalyst was carried out up to four reaction runs (Figure 7). The isolated yields for

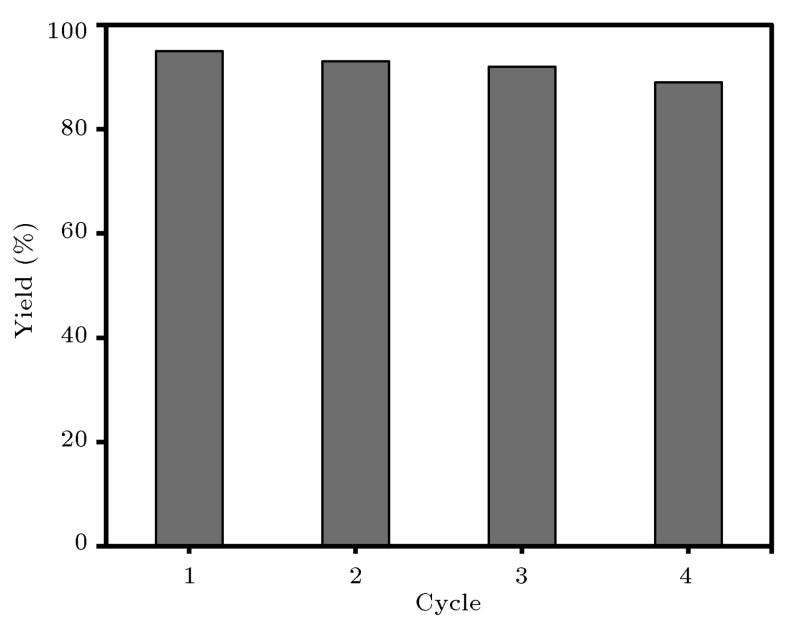

Figure 7. Recyclability of SBA-IL catalyst.

the four runs were found to be $95,93,92$, and $89 \%$, respectively.

\section{Conclusions}

An efficient synthesis of desired pyranonaphthoquinone-fused spirooxindoles was achieved via a one-pot three-component reaction of corresponding isatins, activated methylene reagents, and 2hydroxynaphthalene-1,4-dione under both conventional heating and microwave irradiation in the presence of SBA-IL as a heterogeneous nanocatalyst. Excellent chemical yields, shorter reaction profiles, mild reaction condition, recyclability of the catalyst, and easy workup procedures make the proposed method a sustainable alternative.

\section{Acknowledgments}

We gratefully acknowledge the financial support from the Research Council of Alzahra University and University of Tehran as well as the support of National Elites Foundation of Iran, Tehran (BMN).

\section{References}

1. Kresge, C.T., Leonowicz, M.E., Roth, W.J., Vartuli, J.C., and Beck, J.S. "Ordered mesoporous molecular sieves synthesized by a liquid-crystal template mechanism", Nature, 359, pp. 710-712 (1992). 
2. Hoffmann, F., Cornelius, M., Morell, J., and Fröba, M. "Silica-based mesoporous organic-inorganic hybrid materials", Angew. Chem. Int. Ed., 45(20), pp. 32163251 (2006).

3. Mohammadi Ziarani, G., Lashgari, N., and Badiei, A. "Sulfonic acid-functionalized mesoporous silica (SBA$\left.\mathrm{Pr}-\mathrm{SO}_{3} \mathrm{H}\right)$ as solid acid catalyst in organic reactions", J. Mol. Catal. A: Chem., 397, pp. 166-191 (2015).

4. Lashgari, N., Badiei, A., and Mohammadi Ziarani, G. "Modification of mesoporous silica SBA-15 with different organic molecules to gain chemical sensors: A review", NanoChem. Res., 1(1), pp. 127-141 (2016).

5. Afshani, J., Badiei, A., Lashgari, N., and Mohammadi Ziarani, G. "A simple nanoporous silica-based dual mode optical sensor for detection of multiple analytes $\left(\mathrm{Fe}^{3+}, \mathrm{Al}^{3+}\right.$ and $\left.\mathrm{CN}^{-}\right)$in water mimicking XOR logic gate", RSC Adv., 6, pp. 5957-5964 (2016).

6. Hajiaghababaei, L., Ghasemi, B., Badiei, A., Goldooz, H., Ganjali, M.R., and Ziarani, G.M. "Aminobenzenesulfonamide functionalized SBA-15 nanoporous molecular sieve: A new and promising adsorbent for preconcentration of lead and copper ions", J. Environ. Sci., 24(7), pp. 1347-1354 (2012).

7. Pérez-Verdejo, A., Sampieri, A., Pfeiffer, H., RuizReyes, M., Santamaría, J.-D., and Fetter, G. "Nanoporous composites prepared by a combination of SBA-15 with Mg-Al mixed oxides. Water vapor sorption properties", Beilstein J. Nanotechnol., 5, pp. 1226-1234 (2014).

8. Fathi Vavsari, V., Mohammadi Ziarani, G., and Badiei, A. "The role of SBA-15 in drug delivery", $R S C$ Adv., 5(111), pp. 91686-91707 (2015).

9. Mohammadi Ziarani, G., Hassanzadeh, Z., Gholamzadeh, P., Asadi, S., and Badiei, A. "Advances in click chemistry for silica-based material construction", RSC Adv., 6(26), pp. 21979-22006 (2016).

10. Liu, Y., Peng, J., Zhai, S., Li, J., Mao, J., Li, M., Qiu, H., and Lai, G. "Synthesis of ionic liquid functionalized SBA-15 mesoporous materials as heterogeneous catalyst toward Knoevenagel condensation under solventfree conditions", Eur. J. Inorg. Chem., 2006(15), pp. 2947-2949 (2006).

11. Pârvulescu, V.I., and Hardacre, C. "Catalysis in ionic liquids", Chem. Rev., 107(6), pp. 2615-2665 (2007).

12. Esposito, G., Bourguet-Kondracki, M.-L., Mai, L.H., Longeon, A., Teta, R., Meijer, L., Van Soest, R., Mangoni, A., and Costantino, V. "Chloromethylhalicyclamine B, a marine-derived protein kinase CK1 $\delta / \varepsilon$ inhibitor", J. Nat. Prod., 79(11), pp. 2953-2960 (2016).

13. Zeinyeh, W., Esvan, Y.J., Nauton, L., Loaëc, N., Meijer, L., Théry, V., Anizon, F., Giraud, F., and Moreau, P. "Synthesis and preliminary in vitro kinase inhibition evaluation of new diversely substituted pyrido[3,4g]quinazoline derivatives", Bioorg. Med. Chem. Lett., 26(17), pp. 4327-4329 (2016).

14. Sundberg, R.J., The Chemistry of Indoles; Academic Press: New York (1996).

15. Abdel-Rahman, A.H., Keshk, E.M., Hanna, M.A., and El-Bady, S.M. "Synthesis and evaluation of some new spiro indoline-based heterocycles as potentially active antimicrobial agents", Bioorg. Med. Chem., 12(9), pp. 2483-2488 (2004).

16. Lashgari, N. and Mohammadi Ziarani, G. "Synthesis of heterocyclic compounds based on isatin through 1,3dipolar cycloaddition reactions", Arkivoc, 2012 (1), pp. 277-320 (2012).

17. Mohammadi Ziarani, G., Moradi, R., and Lashgari, N. "Asymmetric synthesis of chiral 3,3-disubstituted oxindoles using isatin as starting material", Tetrahedron: Asymmetry, 26, pp. 517-541 (2015).

18. Mohammadi Ziarani, G., Moradi, R., and Lashgari, N. "Synthesis of spiro-fused heterocyclic sca olds through multicomponent reactions involving isatin", Arkivoc, 2016(1), pp. 1-81 (2016).

19. Ghahremanzadeh, R., Amanpour, T., and Bazgir, A. "An efficient, three-component synthesis of spiro [benzo[g] chromene- $4,3^{\prime}$-indoline]-3-carbonitrile and spiro [indoline-3, $5^{\prime}$-pyrano[2,3- $\left.d\right]$ pyrimidine]- $6{ }^{\prime}-$ carbonitrile derivatives", J. Heterocycl. Chem., 46(6), pp. 1266-1270 (2009).

20. Mobinikhaledi, A., Foroughifar, N., and Fard, M.A.B. "Simple and efficient method for three-component synthesis of spirooxindoles in aqueous and solvent-free media", Synth. Commun., 41(3), pp. 441-450 (2011).

21. Pan, F.-F., Yu, W., Qi, Z.-H., Qiao, C., and Wang, X.-W. "Efficient construction of chiral spiro[benzo[g]chromene-oxindole] derivatives via organocatalytic asymmetric cascade cyclization", Synthesis, 46(09), pp. 1143-1156 (2014).

22. Zhao, H.-W., Li, B., Tian, T., Meng, W., Yang, Z., Song, X.-Q., Chen, X.-Q., and Pang, H.-L. "Highly enantioselective synthesis of chiral pyranonaphthoquinone-fused spirooxindoles through organocatalytic three-component cascade reactions", Eur. J. Org. Chem., 2015(15), pp. 3320-3326 (2015).

23. Gholamzadeh, P., Mohammadi Ziarani, G., Lashgari, N., Badiei, A., and Asadiatouei, P. "Silica functionalized propyl sulfonic acid $\left(\mathrm{SiO}_{2}-\mathrm{Pr}-\mathrm{SO}_{3} \mathrm{H}\right)$ : An efficient catalyst in organic reactions", J. Mol. Catal. A: Chem., 391, pp. 208-222 (2014).

24. Lashgari, N., Mohammadi Ziarani, G., Badiei, A., and Zarezadeh-Mehrizi, M. "Application of sulfonic acid 
functionalized SBA-15 as a new nanoporous acid catalyst in the green one-pot synthesis of spirooxindole4H-pyrans", J. Heterocycl. Chem., 51, pp. 1628-1633 (2014).

25. Gholamzadeh, P., Mohammadi Ziarani, G., Badiei, A., Abolhassani Soorki, A., and Lashgari, N. "Efficient green synthesis of isoindigo derivatives using sulfonicacid-functionalized nanoporous silica (SBA-Pr-SO3H) catalyst and study of their antimicrobial properties", Res. Chem. Intermed., 39(9), pp. 3925-3936 (2013).

26. Mohammadi Ziarani, G., Faramarzi, S., Lashgari, N., and Badiei, A. "A simple and clean method for multicomponent synthesis of spiro[indoletetrahydropyrano(2,3-d)pyrimidine] derivatives using SBA-Pr-SO3H as catalyst under solvent-free conditions", J. Iran. Chem. Soc., 11(3), pp. 701-709 (2014).

27. Mohammadi Ziarani, G., Hosseini Nasab, N., Rahimifard, M., Badiei, A., and Abolhassani Soorki, A. "Synthesis of dihydropyrido[2,3- $d]$ pyrimidine derivatives in the presence of sulfonic acid functionalized SBA- 15 and the study of their antimicrobial activities", Sci. Iranica, 22(6), pp. 2319-2325 (2015).

28. Mohammadi Ziarani, G., Hosseini Mohtasham, N., Lashgari, N., and Badiei, A. "Efficient one-pot synthesis of $2 \mathrm{H}$-indazolo[2,1-b]phthalazinetrione derivatives with amino-functionalized nanoporous silica (SBA-Pr$\mathrm{NH}_{2}$ ) as catalyst", Res. Chem. Intermed., 41(10), pp. 7581-7591 (2015).

29. Mohammadi Ziarani, G., Hosseini Nasab, N., Rahimifard, M., and Abolhasani Soorki, A. "One-pot synthesis of pyrido[2,3- $d]$ pyrimidine derivatives using sulfonic acid functionalized SBA-15 and the study on their antimicrobial activities", J. Saudi Chem. Soc., 19(6), pp. 676-681 (2015).

30. Lashgari, N., Mohammadi Ziarani, G., Badiei, A., and Gholamzadeh, P. "Knoevenagel condensation of isatins with malononitrile/ethyl cyanoacetate in the presence of sulfonic acid functionalized silica ( $\left.\mathrm{SBA}-\mathrm{Pr}-\mathrm{SO}_{3} \mathrm{H}\right)$ as a new nano-reactor", Eur. J. Chem., 3(3), pp. 310-313 (2012).

31. Mohammadi Ziarani, G., Lashgari, N., and Badiei, A. "Green synthesis of spiro[indoline-3,9'-xanthene]trione derivatives using sulfonic acid functionalized SBA15 as a new nanoporous acid catalyst", Sci. Iranica, 20(3), pp. 580-586 (2013).

32. Seyedakbari, L., Mohammadi Ziarani, G., Badiei, A., Yadavi, M., Hajiabbasi, P., and Soorki, A.A. "Multicomponent synthesis of benzo[4,5]imidazo[1,2a]pyrimidine derivatives using novel ionic liquid supported nanoporous silica and their antimicrobial properties", Rev. Chim., 64(8), pp. $832-837$ (2013).

33. Mohammadi Ziarani, G., Seyedakbari, L., Asadi, S., Badiei, A., and Yadavi, M. "Ionic liquid supported nanoporous silica (SBA-IL) as an efficient and heterogeneous catalyst in the domino synthesis of polyhydroquinoline derivatives", Res. Chem. Intermed., 42(2), pp. 499-509 (2016).
34. Gu, Y., and Li, G. "Ionic liquids-based catalysis with solids: State of the art", Adv. Synth. Catal., 351(6), pp. 817-847 (2009).

35. Karimi, B., Zamani, A., and Mansouri, F. "Activity enhancement in cyanation of aryl halides through confinement of ionic liquid in the nanospaces of SBA15-supported Pd complex", RSC Adv., 4(101), pp. 57639-57645 (2014).

36. Karimi, B., and Vafaeezadeh, M. "SBA-15functionalized sulfonic acid confined acidic ionic liquid: a powerful and water-tolerant catalyst for solvent-free esterifications", Chem. Commun., 48(27), pp. 3327-3329 (2012).

37. Davarpanah, J., Rezaee, P., and Elahi, S. "Synthesis and characterization of a porous acidic catalyst functionalized with an imidazole ionic liquid, and its use for synthesis of phthalazinedione and phthalazinetrione heterocyclic compounds", Res. Chem. Intermed., 41(12), pp. 9903-9915 (2015).

38. Bazgir, A., Hosseini, G., and Ghahremanzadeh, R. "Copper ferrite nanoparticles: an efficient and reusable nanocatalyst for a green one-pot, three-component synthesis of spirooxindoles in water", ACS. Comb. Sci., 15(10), pp. 530-534 (2013).

39. Lee, H.I., Kim, J.H., Stucky, G.D., Shi, Y., Pak, C., and Kim, J.M. "Morphology-selective synthesis of mesoporous SBA-15 particles over micrometer, submicrometer and nanometer scales", J. Mater. Chem., 20(39), pp. 8483-8487 (2010).

\section{Biographies}

Ghodsi Mohammadi Ziarani was born in Iran in 1964. She received her BSc degree in Chemistry from the Teacher Training University, Tehran, Iran, in 1987; MSc degree in Organic Chemistry from the same university, under the supervision of Professor Jafar Asgarin and Professor Mohammad Ali Bigdeli, in 1991; and $\mathrm{PhD}$ degree in Asymmetric Synthesis (Biotransformation) from Laval University, Quebec, Canada, under the supervision of Professor Chenevert, in 2000. She is full professor in the Science Faculty of Alzahra University. Her research interests include organic synthesis, heterocyclic synthesis, asymmetric synthesis, natural products synthesis, synthetic methodology, and applications of nano-heterogeneous catalysts in multicomponent reactions.

Hoda Mollabagher was born in 1987, in Tehran, Iran. She received her BSc degree in Pure Chemistry from Islamic Azad University, North Tehran Branch, Iran, in 2009, and two MSc degrees in Physical Chemistry from Islamic Azad University, Science and Research Branch, Tehran, Iran, in 2013, and in Organic Chemistry from Alzahra University, Tehran, Iran, in 2016. She is currently working towards her PhD at the Chemistry \& Chemical Engineering Research Center 
of Iran. Her research interests include synthesis of chromens and the application of nano-heterogeneous catalysts in organic synthesis and multicomponent reactions.

Negar Lashgari was born in 1985 in Tehran, Iran. She received her BSc degree in Applied Chemistry from Kharazmi University, Karaj, Iran, in 2008, and her MSc degree in Organic Chemistry from Alzahra University, Tehran, Iran, in 2011 under the supervision of Dr. Ghodsi Mohammadi Ziarani. She obtained her PhD degree in Nano-chemistry from University of Tehran under the supervision of Dr. Alireza Badiei and Dr. Ghodsi Mohammadi Ziarani in 2017. Her research field is synthesis and functionalization of mesoporous silica materials and their application as nano- heterogeneous catalysts in multicomponent reactions and fluorescent chemosensors for detection of various anions and cations.

Alireza Badiei was born in Iran in 1965. He received $\mathrm{BSc}$ and $\mathrm{MSc}$ degrees in Chemistry and Inorganic Chemistry from the Teacher Training University, Tehran, Iran, in 1988 and 1991, respectively, and his PhD degree in Synthesis and Modification of Nanoporous Materials from Laval University, Quebec, Canada, in 2000. He is currently full professor in the Chemistry Faculty of Tehran University. His research interests include nanoporous materials synthesis, modification of nanoporous materials, and application of nano catalysts in synthesis of biological active compounds. 